\title{
Contribution of Risk Factors to the Appearance of Type 2 Diabetes among Patients Treated in Two University Hospitals in Togo, West Africa
}

\author{
Toussaint Bawou Banakinao1,2*, Mamatchi Melila², Comlan Evariste S. Mitchikpe ${ }^{1}$ \\ ${ }^{1}$ School of Nutrition, Food Sciences and Technology, Faculty of Agricultural Sciences, University of Abomey-Calavi, \\ Cotonou, Benin \\ ${ }^{2}$ Department of Biochemistry/Nutrition, Faculty of Sciences, University of Lome, Lome, Togo \\ Email: *bawoubana@gmail.com
}

How to cite this paper: Banakinao, T.B., Melila, M. and Mitchikpe, C.E.S. (2021) Contribution of Risk Factors to the Appearance of Type 2 Diabetes among Patients Treated in Two University Hospitals in Togo, West Africa. Open Access Library Journal, 8: e7959.

https://doi.org/10.4236/oalib.1107959

Received: September 13, 2021

Accepted: October 9, 2021

Published: October 12, 2021

Copyright $\odot 2021$ by author(s) and Open Access Library Inc.

This work is licensed under the Creative Commons Attribution International License (CC BY 4.0).

http://creativecommons.org/licenses/by/4.0/

\begin{abstract}
Objective: Diabetes is one of the most common pathologies in the world. Although its risk factors are known, it cannot be confirmed that all risk factors have a constant contribution to the development of type 2 diabetes from one population to another. In this regard, this retrospective study aims to assess the contribution of different risk factors in occurrence of type 2 diabetes in the Togolese population. Methods: In this retrospective study conducted between August and October 2020, we obtained information from 338 patients admitted to Sylvanus Olympio and Campus University Hospitals. Using a detailed questionnaire, socio-demographic data, anthropometric measurements, data on lifestyle and family history were collected. Results: The risk factors significantly associated with the onset of type 2 diabetes are age $(\mathrm{OR}=1.03 ; 95 \% \mathrm{CI}(1.01-1.06), \mathrm{P}=0.004)$, gender $(\mathrm{OR}=0.52 ; 95 \% \mathrm{CI}$ (0.34-0.80), $\mathrm{P}=0.003)$, ethnic group $(\mathrm{P}=0.001)$, the diabetic status of the direct ascendants $(\mathrm{OR}=3.78$; 95\% CI $(1.98-7.22), \mathrm{P}<0.001)$, siblings' diabetic status $(\mathrm{OR}=6.31 ; 95 \% \mathrm{CI}(3.23-12.33), \mathrm{P}<0.001)$, overweight and obesity $(\mathrm{OR}=2.45 ; 95 \% \mathrm{CI}(1.58-3.79), \mathrm{P}<0.001)$, residence $(\mathrm{P}<0.001)$ and sedentary lifestyle $(\mathrm{OR}=2.80,95 \% \mathrm{CI}(1.41-5.56), \mathrm{p}=0.002)$. Conclusion: The prevention of type 2 diabetes based on the contribution of risk factors would be effective in avoiding a sedentary lifestyle, overweight and obesity which are easier to influence.
\end{abstract}

\section{Subject Areas}

Diabetes \& Endocrinology

\section{Keywords}

Type 2 Diabetes, Risk Factors, Retrospective Case-Control Study, Togo 


\section{Introduction}

The prevalence of type 2 diabetes is on the rise globally. In 2017, around 425 million people aged 20 - 79 years worldwide were diabetic or $8.8 \%$ of adults and if this trend continues by 2045, around 629 million people aged $20-79$ years will be with diabetes [1]. Type 2 diabetes represents $10.7 \%$ of global mortality from all causes, or one death every eight seconds [1].

Contrary to popular thinking that viewed diabetes as rich people's disease, there is evidence that it is prevailing in low and middle-income countries [2].

Even though the risk factors for type 2 diabetes are generally known, their respective contribution to the development of type 2 diabetes remains to be determined, especially among the Togolese population, which had a prevalence of type 2 diabetes of $4.7 \%$ in 2017 [2]. Moreover, studies on type 2 diabetes in the Togolese population about the main risk factors causing the development and increase of type 2 diabetes are non-existent to date. In this regard, this retrospective study aims to assess the contribution of risk factors to the development of type 2 diabetes among patients by specifically seeking to establish the association between risk factors and the development of type 2 diabetes and also to determine the risk factors that most contributed to the development of type 2 diabetes.

\section{Patients and Methods}

\subsection{Participants}

This retrospective case-control study was carried out in two Hospitals which are Sylvanus OLYMPIO University Hospital and Campus University Hospital between August and October 2020. Study concerned individuals of both sexes numbering 338 people and divided into 169 cases and 169 witnesses. The cases are patients having previously been diagnosed with type 2 diabetes and received in consultation or hospitalized for hyperglycemia, high blood pressure and neurological problems in the internal medicine department of the Sylvanus OLYMPIO University Hospital; the internal medicine and neurology departments of the Campus University Hospital for the period from August 12, 2020 to October 12, 2020.

Women whose diabetes was first diagnosed during pregnancy were excluded from the study.

The control group consisted of patients whose age matched that of the cases; diagnosed without diabetes on the basis of glycated hemoglobin results and also received in consultation or hospitalized in one of these hospitals for high blood pressure, neurological problems ...

\subsection{Data Collected}

Each group had a distinct questionnaire. For the cases, the information collected during the investigation was about the period before the diagnosis of type 2 diabetes. The investigations help collected the following data: 


\subsubsection{Socio-Demographic Data}

It relate to gender, age, ethnicity and area of residence. The age groups were defined according to the WHO standard age groups [3]: <44 years, $45-59$ years, 60 - 69 years, 70 - 79 years, 80 years and above.

\subsubsection{Anthropometric Measurements}

For type 2 diabetics, the weight and height considered were those recorded in the medical record at diagnosis of type 2 diabetes. For controls, weight and height gains recorded in the medical record and closest to those of the matched case were considered; in the absence of this information, new measurements were taken for controls according to WHO recommendations [4].

\subsubsection{Lifestyle and Physical Activity}

Dietary history, helped collect data related to the participants sugar and alcohol consumption. Thus, we have:

\section{1) Overconsumption of sugar}

Chronic consumption of more than 25 grams of sugar per day indicates overconsumption [5]. All the study participants consuming or who regularly consumed more than 25 grams of sugar per day were considered to be over-consuming sugar.

\section{2) Harmful use of alcohol}

The classification for the harmful use of alcohol was made according to WHO recommendations [6].

Thus, type 2 diabetics who had regularly consumed before the diagnosis of diabetes more than 3 standard alcoholic drinks for men and 2 standard alcoholic drinks for women were considered to make harmful use of alcohol. The same criteria also apply to the witnesses.

\section{3) Smoking}

Individuals were categorized into two groups namely smoker and non-smoker; former-smokers were considered smokers.

\section{4) The practice of physical activity}

The WHO recommendation [7] for physical activity is 150 minutes of a moderate-intensity endurance activity or at least 75 minutes of sustained-intensity endurance activity, or a combination for the age group from 18 - 64 years old.

For people aged 65 and over, physical activity includes recreation, travel such as walking, cycling, professional activities, household chores, playful activities, sports or planned exercise, in the daily, family or community context.

\subsection{Ethical Considerations}

The surveys were carried out under the authorization of the directors of the two universities hospitals centers with the free and informed consent of the participants. A local language translation was made for participants who could not express themselves in French. The confidentiality of their answers was guaranteed to them. 


\subsection{Data Analysis}

Data collected were entered into the Excel 2019 spreadsheet and then imported into SPSS version 20 software for analysis. The statistical analysis of the data was carried out first by describing the people as a whole and secondly in the two groups (cases and controls) using the following procedure:

First, the univariate analysis made it possible to describe each variable presented in tabular form. Then, the bivariate analysis made it possible to compare the variables two by two to determine the correlation coefficients, the Chi2 independence test and the odds ratio to determine the chances of occurrence of type 2 diabetes according to risk factors. Finally, multivariate analysis was performed to establish binary logistic regression models to explain the link that would exist between the different risk factors likely to cause the development of type 2 diabetes.

The significance level for both univariate and multivariate analysis was set at $5 \%(\mathrm{P}<0.05)$.

\section{Results}

During the study period, 338 patients were recruited and divided into 169 type 2 diabetics representing the cases and 169 non-diabetics representing the controls (Tables 1-3).

\subsection{Sociodemographic Characteristics of the Individuals Surveyed}

The 40 - 59 years age group was the most represented in both groups. The mean age in diabetics is $57.83 \pm 11.77$ years and $55.48 \pm 10.41$ years in non-diabetics with a significant predominance of the female participants among type 2 diabetics (63.9\%).

The South Togo ethnic group and individuals dwelling in the urban area were the most represented among type 2 diabetics.

\subsection{Anthropometric Measurements}

Overweight and obesity were significantly important (64.5\%) in type 2 diabetic patients, On the other hand, in controls, subjects with a BMI less than $25 \mathrm{~kg} / \mathrm{m}^{2}$ predominated (57.4\%).

\subsection{Overconsumption of Sugar}

The distribution of type 2 diabetics and controls according to the quantity of sugar usually consumed daily showed higher sugar consumption in the control group compared to type 2 diabetics group, but this difference is statically insignificant (52.7\% vs. $47.9 \%$; OR $=0.83,95 \% \mathrm{CI}(0.54-1.27), \mathrm{P}=0.384)$.

\subsection{Harmful Use of Alcohol}

The harmful use of alcohol has been observed more in type 2 diabetics group. 
Table 1. Description of the sample and link between diabetes and risk factors.

\begin{tabular}{|c|c|c|c|c|c|}
\hline \multirow{2}{*}{ Variable } & Cases & Controls & \multirow{2}{*}{ OR } & \multirow{2}{*}{$95 \%$ CI } & \multirow{2}{*}{$\mathrm{P}$} \\
\hline & $\mathrm{n}(\%)$ & $\mathrm{n}(\%)$ & & & \\
\hline \multicolumn{6}{|l|}{ Age (years) } \\
\hline $19-29$ & $1(0.6)$ & $1(0.6)$ & & & \\
\hline $30-39$ & $14(8.3)$ & $11(6.5)$ & & & \\
\hline $40-49$ & $54(32)$ & $23(13.6)$ & & & \\
\hline $50-59$ & $46(27.2)$ & $63(37.3)$ & & & \\
\hline $60-69$ & $36(21.3)$ & $41(24.3)$ & & & \\
\hline $70-79$ & $14(8.3)$ & $22(13.0)$ & & & \\
\hline$>79$ & $4(2.4)$ & $8(4.7)$ & & & \\
\hline Total & $169(100)$ & $169(100)$ & & & \\
\hline Median (Max; Min) & $57(100 ; 28)$ & $56(83 ; 28)$ & & & \\
\hline Mean \pm ET & $57.83 \pm 11.77$ & $55.48 \pm 10.41$ & & & \\
\hline \multicolumn{6}{|c|}{ Age at diagnosis of type 2 diabetes (years) } \\
\hline $19-29$ & $6(1.8)$ & & & & \\
\hline $30-39$ & $20(5.9)$ & & & & \\
\hline $40-49$ & $45(13.3)$ & & & & \\
\hline $50-59$ & $51(15.1)$ & & & & \\
\hline $60-69$ & $32(9.5)$ & & & & \\
\hline $70-79$ & $11(3.3)$ & & & & \\
\hline$>79$ & $4(1.2)$ & & & & \\
\hline Total & $169(100)$ & & & & \\
\hline Median (Max; Min) & $53(94 ; 19)$ & & & & \\
\hline Mean \pm ET & $52.04 \pm 12.33$ & & & & \\
\hline Sex & & & 0.520 & $0.34-0.80$ & 0.003 \\
\hline Male & $61(36.1)$ & $88(52.1)$ & & & \\
\hline Female & $108(63.9)$ & $81(47.9)$ & & & \\
\hline Total & $169(100)$ & $169(100)$ & & & \\
\hline Ethnic group & & & & & 0.001 \\
\hline North & $42(24.85)$ & $67(39.6)$ & & & \\
\hline South & $103(60.9)$ & $93(55)$ & & & \\
\hline Foreigners & $24(14.2)$ & $9(5.3)$ & & & \\
\hline Total & $169(100)$ & $169(100)$ & & & \\
\hline $\mathrm{T} 2 \mathrm{D}^{\star}$ Residence area & & & & & 0.000 \\
\hline Urban & $103(60.9)$ & $139(82.2)$ & & & \\
\hline Rural & $45(26.6)$ & $17(10.1)$ & & & \\
\hline Alternation & $21(12.4)$ & $13(7.7)$ & & & \\
\hline Total & $169(100)$ & $169(100)$ & & & \\
\hline $\mathrm{T} 2 \mathrm{D}^{*} \mathrm{BMI}$ & & & 2.45 & $1.58-3.79$ & 0.000 \\
\hline $\mathrm{BMI}>25 \mathrm{~kg} / \mathrm{m}^{2}$ & $109(64.5)$ & $72(42.6)$ & & & \\
\hline $\mathrm{BMI}<25 \mathrm{~kg} / \mathrm{m}^{2}$ & $60(35.5)$ & $97(57.4)$ & & & \\
\hline Total & $169(100)$ & $169(100)$ & & & \\
\hline
\end{tabular}




\begin{tabular}{|c|c|c|c|c|c|}
\hline Continued & & & & & \\
\hline $\mathrm{T} 2 \mathrm{D}^{\star}$ Consumption of sugar & & & 0.83 & $0.54-1.27$ & 0.384 \\
\hline consumption of sugar $>25 \mathrm{~g} /$ day & $81(47.9)$ & $89(52.7)$ & & & \\
\hline consumption of sugar $<25 \mathrm{~g} /$ day & $88(52.1)$ & $80(47.3)$ & & & \\
\hline Total & $169(100)$ & $169(100)$ & & & \\
\hline $\mathrm{T} 2 \mathrm{D}^{\star}$ Harmful use of alcohol & & & 1.54 & $0.61-3.87$ & 0.358 \\
\hline $\begin{array}{l}>2(\text { female }) \text { or } 3 \text { (male) } \\
\text { glasses/day }\end{array}$ & $12(7.1)$ & $8(4.73)$ & & & \\
\hline $\begin{array}{l}<2(\text { female }) \text { or } 3 \text { (male) } \\
\text { glasses/day }\end{array}$ & $157(92.9)$ & $161(95.27)$ & & & \\
\hline Total & $169(100)$ & $169(100)$ & & & \\
\hline $\mathrm{T} 2 \mathrm{D}^{\star}$ Smoking & & & 1.85 & $0.61-5.63$ & 0.275 \\
\hline Smokers & $9(5.3)$ & $5(3)$ & & & \\
\hline Non-Smokers & $160(94.7)$ & $164(97)$ & & & \\
\hline Total & $169(100)$ & $169(100)$ & & & \\
\hline TD2* Sedentary lifestyle & & & 2.80 & $1.41-5.56$ & 0.002 \\
\hline Sedentary & $32(18.9)$ & $13(7.7)$ & & & \\
\hline Non Sedentary & $137(81.1)$ & $156(92.3)$ & & & \\
\hline Total & $169(100)$ & $169(100)$ & & & \\
\hline T2D*Diabetic parents & & & 3.778 & $1.98-7.22$ & 0.000 \\
\hline Diabetic parents & $43(25.4)$ & $14(8.3)$ & & & \\
\hline Non-Diabetic parents & $126(74.6)$ & $155(91.7)$ & & & \\
\hline Total & $169(100)$ & $169(100)$ & & & \\
\hline T2D ${ }^{\star}$ Diabetic status of siblings & & & 6.312 & $3.23-12.33$ & 0.000 \\
\hline Diabetic siblings & $55(32.5)$ & $12(7.1)$ & & & \\
\hline Non-diabetic siblings & $114(67.5)$ & 157 (92.9) & & & \\
\hline Total & $169(100)$ & $169(100)$ & & & \\
\hline
\end{tabular}

T2D: Type 2 diabetes; CI: confidence interval; OR: Odd Ratio; $\mathrm{p}$ : $\mathrm{p}$ value; ${ }^{* *} \mathrm{p}<0.001 .{ }^{* *} \mathrm{p}<0.01 .{ }^{*} \mathrm{p}<0.05$.

However, the difference was statistically insignificant (7.1\% vs. $4.7 \%$; $\mathrm{OR}=1.54$, 95\% CI (0.61 - 3.87), $\mathrm{P}=0.358)$.

\subsection{Smoking}

Type 2 diabetics were also the most represented among smokers but again with a statistically insignificant difference compared to controls $(5.3 \%$ vs. $3 \%$; OR $=$ $1.85,95 \%$ CI (0.61 - 5.63), $\mathrm{P}=0.275)$.

\subsection{Lifestyle and Physical Activity}

A sedentary lifestyle was significantly associated with the development of type 2 diabetes in our study. On the one hand, type 2 diabetics are predominant among sedentary people $(18.9 \%$ vs. $7.7 \%$; $\mathrm{OR}=2.80,95 \% \mathrm{CI}(1.41-5.56), \mathrm{P}=0.002)$ and non-type 2 diabetics predominant among non-sedentary people $(81.1 \%$ vs. 92.3\%; $\mathrm{OR}=2.80,95 \% \mathrm{CI}(1.41-5.56), \mathrm{P}=0.002)$. 
Table 2. Binary logistic regression between type 2 diabetes and its risk factors.

\begin{tabular}{lcccc}
\hline & Coef & OR & $95 \%$ CI & P \\
\hline Age (years) & 0.033 & 1.03 & $1.011-1.058$ & $0.004^{* * *}$ \\
Gender (1) & 0.625 & 1.87 & $1.085-3.214$ & $0.024^{*}$ \\
Ethnic group & & & & $0.011^{*}$ \\
$\quad$ Ethnic group (1) & 1.229 & 3.42 & $1.318-8.868$ & 0.011 \\
$\quad$ Ethnic group (2) & -0.288 & 0.75 & $0.426-1.319$ & 0.318 \\
Obesity (1) & 0.635 & 1.89 & $1.110-3.205$ & $0.019^{*}$ \\
Residence & & & & $0.000^{* * *}$ \\
$\quad$ Residence (1) & 1.091 & 2.98 & $1.284-6.904$ & $0.011^{*}$ \\
$\quad$ Residence (2) & 1.558 & 4.75 & $2.309-9.761$ & $0.000^{* * *}$ \\
Sedentary lifestyle (1) & 0.894 & 2.45 & $1.082-5.524$ & $0.032^{*}$ \\
Smoking (1) & 1.042 & 2.84 & $0.704-11.425$ & 0.143 \\
Harmful use of alcohol (1) & 0.317 & 1.37 & $0.457-4.120$ & 0.572 \\
Consumption of sugar (1) & -0.234 & 0.79 & $0.468-1.339$ & 0.383 \\
Diabetic parents (1) & 0.980 & 2.66 & $1.232-5.758$ & $0.013^{*}$ \\
Diabetic siblings (1) & 1.798 & 6.04 & $2.851-12.794$ & $0.000^{* * *}$ \\
Constant & -3.489 & 0.03 & & $0.000^{* * *}$ \\
\hline
\end{tabular}

Table 3. Coding of nominal variables.

\begin{tabular}{|c|c|c|c|}
\hline \multirow{2}{*}{ Variables } & \multirow{2}{*}{ Frequency } & \multicolumn{2}{|c|}{ Parameter coding } \\
\hline & & (1) & (2) \\
\hline \multicolumn{4}{|l|}{ Gender } \\
\hline $\mathrm{F}$ & 189 & 1 & \\
\hline M & 149 & 0 & \\
\hline \multicolumn{4}{|l|}{ Ethnic group } \\
\hline Foreigners & 33 & 1 & 0 \\
\hline North & 109 & 0 & 1 \\
\hline South & 196 & 0 & 0 \\
\hline \multicolumn{4}{|l|}{ Obesity } \\
\hline Yes & 181 & 1 & \\
\hline No & 157 & 0 & \\
\hline \multicolumn{4}{|l|}{ Residence } \\
\hline Alternation & 34 & 1 & 0 \\
\hline Rural & 62 & 0 & 1 \\
\hline Urban & 242 & 0 & 0 \\
\hline \multicolumn{4}{|c|}{ Sedentary lifestyle } \\
\hline Yes & 45 & 1 & \\
\hline No & 293 & 0 & \\
\hline \multicolumn{4}{|l|}{ Smoking } \\
\hline Yes & 14 & 1 & \\
\hline No & 324 & 0 & \\
\hline
\end{tabular}




\section{Continued}

\begin{tabular}{lcl}
\hline Harmful use of alcohol & 20 & 1 \\
Yes & 318 & 0 \\
No & & \\
Consumption of sugar & 170 & 1 \\
Yes & 168 & 0 \\
No & & \\
Diabetic Parents & 57 & 1 \\
Yes & 281 & 0 \\
No & & \\
Diabetic siblings & 67 & 1 \\
Yes & 271 & 0 \\
No & & \\
\hline
\end{tabular}

\subsection{Family History}

The 44 - 59 years age group is the most diagnosed with type 2 diabetes with a mean age of $52.04 \pm 12.33$ years.

The distribution of cases and controls according to the diabetic status of their direct ascendant shows that the development of type 2 diabetes is significantly associated with the diabetic status of direct ascendants (OR = 3.78, 95\% CI (1.98 7.22), $\mathrm{P}<0.001)$. The proportion of direct diabetic ascendants in the cases was greater than the controls $(25.4 \%$ versus $8.3 \%)$ and the proportion of direct ascendants without type 2 diabetes in the controls was greater than the cases (91.7\% vs. $74.6 \%)$.

The association between type 2 diabetes and sibling diabetic status was statistically significant $(\mathrm{OR}=6.31,95 \% \mathrm{CI}(3.23-12.33), \mathrm{P}<0.001)$. Siblings with type 2 diabetes predominated over controls (32.5\% vs. $7.1 \%)$ and on the other hand. siblings without type 2 diabetes were in greater proportion among controls compared to cases ( $92.9 \%$ vs. $67.5 \%)$.

\section{Discussion}

This study noted the contribution of different risk factors to the development of type 2 diabetes. The predominance of type 2 diabetics in the $40-49$ years age group has also been observed in the Ivorian population at a rate of 29.6, i.e. in a lower proportion [8]. The decrease in the prevalence from 50 years old is explained by the high mortality which is generally observed in populations of diabetics and especially in low or middle-income countries including Togo with the main cause of late diagnoses and lack of appropriate care [9].

The diagnosis of type 2 diabetes in this age group could be explained by the fact that type 2 diabetes usually appears beyond the age of 40 and due to the lack of symptoms, the diagnosis is made 5 to 10 years later with the development of complications [10]. 
In many other studies like some of which were carried out in Togo [11], the female sex was more associated with the presence of type 2 diabetes and this was very well observed in recent data of the International Diabetes Federation on Africa where the female sex was the most represented in all age groups [9].

We observed that having a $\mathrm{BMI} \geq 25 \mathrm{Kg} / \mathrm{m}^{2}$ increased by 2.45 times the chances of being type 2 diabetic. Chloé et al. [12] in France also observed a significant association between overweight/obesity and appearance of type 2 diabetes in a proportion of $84.5 \%$ and $74.6 \%$. This trend towards overweight and obesity could be justified by a sedentary lifestyle but also by the African context which considers being overweight is an indicator of social success, good health and prosperity. This does not encourage taking initiatives to lose weight. Thus, overweight and obesity would facilitate the development of type 2 diabetes in the sense that it induces insulin resistance which is explained by the accumulation of adipose tissue inside the abdominal cavity which is associated with glucose intolerance and hyperinsulinemia [13]. It should also be noted that the proportion of women with a $\mathrm{BMI} \geq 25 \mathrm{Kg} / \mathrm{m}^{2}$ was higher than men proportion $(28.4 \%$ vs. $14.3 \%)$ [14].

The positive association between sedentary lifestyle and the development of type 2 diabetes observed in our study was also observed successively by Silvera $e t$ al. [15] in Ile de France at a rate of $66.8 \%$ and by Coulibaly et al. [16] in Mali at a rate of $57 \%$. The action of a sedentary lifestyle in the development of type 2 diabetes was also mentioned by WHO studies which demonstrate that low physical activity leads to hyperglycemia, overweight, obesity and all the risks favourable to the development of type 2 diabetes [17]. Women were also predominant in our study. In 2016, WHO' study [17] that looked for physical activity levels by gender showed that in all WHO regions and country groups (by income), women were less active than men.

The association between living in an urban area and the appearance of type 2 diabetes observed was consistent with the results of the IDF, which concluded that the global prevalence of type 2 diabetes is higher in urban than in rural areas (10.2\% vs. $6.9 \%$ ) [1]. With $16.3 \%$ of urban dwellers against $76.2 \%$ of rural dwellers in occupations of intense physical activity such as agriculture [18]; and the level of energy expenditure which is strongly associated with the type of occupation, the large proportion of people with type 2 diabetes in urban areas noted in our study could be explained.

Populations originating from the South Togo were the most represented in our study with a proportion of approximately $61 \%$ among type 2 diabetic patients. The strong urbanization of South Togo compared to the North could explain the high proportion of populations originating from the South Togo among type 2 diabetics. This then agrees with the significant association existing between residence in the urban area and the development of type 2 diabetes found above.

The non-association between sugar consumption and the development of type 
2 diabetes was observed in a study by the French Food Safety Agency (AFSSA) [19] which was also unable to establish a clear link between the consumption of simple carbohydrates and the incidence of type 2 diabetes. This could be explained by the difficulty in easily estimating the sugar from other food sources consumed; the quantity of fat consumed and the level of physical activity which significantly influences the body's sugar stock.

The low proportion of type 2 diabetics among those who used alcohol moderately and the higher proportion of those who used alcohol harmfully is corroborated by Schlienger study [20] which reached the same result. Even if this relationship between alcohol consumption and type 2 diabetes is ambiguous, this could be explained by the fact that moderate and regular alcohol consumption improves insulin sensitivity [21], hence the decrease in the incidence of type 2 diabetes [22]; and conversely, excessive alcohol consumption increases insulin resistance [23]. Thus, moderate and regular consumption of alcohol has a protective effect against the development of type 2 diabetes.

Our results have showed that smoking increases the odds of having type 2 diabetes by 1.85 times. However, the association was not significant. In contrast, other studies by Willi et al. [24]; Eliasson et al. [25] looking at a larger population in the USA also found a significant association between smoking and type 2 diabetes. This association is explained by the fact that nicotine induces insulin resistance [24] [25] hence the increased incidence of type 2 diabetes.

In our study, heredity was associated with type 2 diabetes with 4 times more chance in children of direct ascendants to be diabetes. Steinberg [26] also have observed this association in the American population $(\mathrm{OR}=2)$.

Concerning siblings, the increased chances of having type 2 diabetes by having brothers and/or sisters with type 2 diabetes are corroborated by the results of the study results of Rigalleau et al. [27] who conclude that the risk of type 2 diabetes development increases with the number of family members affected and the agreement in monozygotic twins approaches $100 \%$. This would be due to genetic factors which are more pronounced in the siblings.

This association between the appearance of type 2 diabetes and the family link could be explained based on heredity and the collective adoption in families of a lifestyle favourable to the appearance of type 2 diabetes such as fatty and sweet eating, physical inactivity ...

\section{Conclusions}

This retrospective study concerning type 2 diabetes provided insight into the contribution of multiple risk factors to its occurrence in patients treated in the Sylvanus Olympio University Hospital and campus University Hospital in Togo.

Although the causes are multiple, apart from the harmful use of alcohol, smoking and overconsumption of sugar, which in our study were not statistically significant risk factors for the development of type 2 diabetes, all others like living in an urban environment, sedentary lifestyle and hereditary factors represent 
statistically significant risk factors for the development of type 2 diabetes.

The fact that the female sex was the most affected by this pathology should also lead to further studies to discover the role that gender plays physiologically in the appearance of type 2 diabetes. The insignificance of the harmful use of alcohol and smoking may be due to their low proportion in the population and should not encourage their adoption or excess.

Apart from the other risk factors which are difficult to influence to prevent or even reduce the effects of the disease, we have a sedentary lifestyle and overweight and obesity on which we can act.

The diagnosis of type 2 diabetes among the subjects of our study was generally made unexpectedly following a disease such as malaria or neurological complication. The majority of type 2 diabetes despite their diabetic state ignores the diabetic status of their children. This should lead to a policy of sensitizing parents.

\section{Study Limits}

The limit of this study lies in estimated the quantity of sugar consumed during past years.

Since estimating the quantity of sugar provided by other food besides, table sugar is difficult especially for retrospective study, we have considered the amount of table sugar consumed to assess the overall level of sugar consumption.

\section{Acknowledgements}

We would like to thank all the study participants, the administration of Campus University Hospital and Sylvanus Olympio University Hospital.

Sincere thanks to the staff and manager of the internal medicine department of Sylvanus Olympio University Hospital; the internal medicine and neurology departments of Campus University Hospital.

\section{Conflicts of Interest}

The authors declare that there is no conflict of interest between them.

\section{References}

[1] International Diabetes Federation (2017) IDF Diabetes Atlas. 8th Edition, International Diabetes Federation, Brussels.

[2] World Health Organization (2020) Diabetes. https://www.who.int/fr/news-room/fact-sheets/detail/diabetes

[3] World Health Organization (2002) The World Health Report 2002-Reducing Risks, Promoting Healthy Life. World Health Organization, Geneva.

[4] World Health Organization (1995) Physical Status: The Use and Interpretation of Anthropometry. Report of a WHO Expert Committee. WHO Technical Report Series No. 854, World Health Organization, Geneva.

[5] World Health Organization (2015) Information Note about Intake of Sugars Rec- 
ommended in the WHO Guideline for Adults and Children. Department of Nutrition for Health and Development, World Health Organization, Geneva.

[6] World Health Organization (2000) International Guide for Monitoring Alcohol Consumption and Related Harm. Department of Mental Health and Substance Dependence, World Health Organization, Geneva.

[7] World Health Organization (2010) Global Recommendations on Physical Activity for Health. World Health Organization, Geneva.

[8] Oga, A.S.S, Tebi, A., Aka, J., Adouéni, K.V., Malan, K.A., Kouadio, L.P., et al. (2006) Diabetes in Ivory Coast: Special Epidemiological Features. Medecine Tropicale, 66, 241-246.

[9] International Diabetes Federation (2019) IDF Diabetes Atlas. 9th Edition, International Diabetes Federation, Brussels.

[10] Fédération Française des Diabétiques (2004) Qu'est-ce que le diabète? https://www.federationdesdiabetiques.org/information/diabete

[11] Moukaila, A.R., Mossi, E.K., Nemi, K.D., Kodjo, K., Djagadou, A.K., Balaka, A., et al. (2020) Evaluation of the Level of Knowledge and Practice of Hygieno-Dietary Measures in Diabetic Patients at the Medical-Surgical Clinic of the Sylvanus Olympio University Hospital in Lomé (Togo). International Journal of Diabetes Research, 9, 5-11.

[12] Chloé, L.G.R. (2015) Adhésion aux règles hygiéno-diététiques des patients diabétiques de type 2 et rôle du médecin généraliste dans leur prise en charge à Fréjus et Saint-Raphaël (Var). Med Thesis, University of Nice, Nice.

[13] Boulben, M. (2017) Problématiquemédico-économique du diabète de type 2 dans lecadre de la potentielle entrée sur le marché des inhibiteurs de laSGLT2, nouvelle classemédicamenteuse anti-diabétique. Pharmacy Thesis, University of Laurraine, Laurraine. https://hal.univ-lorraine.fr/hal-01932164/document

[14] World Health Organization (2012) Rapport final de l'enquête STEPS-Togo 2010. https://www.who.int/ncds/surveillance/steps/2010STEPS Report Togo FR.pdf

[15] Silvera, I., Simon, D., Trutt, B., Blanchon, B., Parmentier, M., Hecquard, P., et al. (2000) Description des diabétiques de type 2 d'île de France âgés de 70 ans au plus. Diabetes \& Métabolism, 26, 69-76.

[16] Coulibaly, I. (2012) Problématique des mesures hygiéno-diététiques chez les diabétiques dans les unités de prise en charge du diabète à Bamako créées dans le cadre de la mise en oeuvre de l'approche steps Wise. Thèse, Université des sciences des techniques et des Technologies de Bamako.

[17] World Health Organization (2016) WHO Urges Global Action to Curtail Consumption and Health Impacts of Sugary Drinks. Communiqué de presse Genève. https://www.who.int/news/item/11-10-2016-who-urges-global-action-to-curtail-con sumption-and-health-impacts-of-sugary-drinks

[18] INSEED (National Institute of Statistics and Economic and Demographic Studies) -TOGO (2016) Questionnaire Unifié des Indicateurs de Base du Bien-Être 2015. National Institute of Statistics and Economic and Demographic Studies (Togo), Lomé, 174.

[19] Agence française de Sécurité Sanitaire des Aliments (2004) Glucides et santé: État des lieux, évaluation et recommandations. https://www.anses.fr/fr/system/files/NUT-Ra-Glucides.pdf

[20] Schlienger, J.L. (2004) Alcool et diabète. Métabolismes Hormones Diabètes et Nutrition, 8, 101-108. 
[21] Konrat, C., Mennen, L.I., Caces, E., Lepinay, P., Rakotozafy, F., Forhan, A., et al. (2002) Alcohol Intake and Fasting Insulin in French Men and Women. The DESIR Study. Diabetes \& Metabolism, 28, 116-123.

[22] Howard, A.A., Arnsten J.H. and Gourevitch, M.N. (2004) Effect of Alcohol Consumption on Diabetes Mellitus: A Systematic Review. Annals of Internal Medicine, 140, 211-219. https://doi.org/10.7326/0003-4819-140-6-200403160-00011

[23] Yki-Jarvinen, H. and Nikkila, E.A. (1985) Ethanol Decreases Glucose Utilisation in Healthy Men. The Journal of Clinical Endocrinology \& Metabolism, 61, 941-945. https://doi.org/10.1210/jcem-61-5-941

[24] Willi, C., Bodenmann, P., William, A.G., Faris, P.D. and Cornuz, J. (2007) Active Smoking and the Risk of Type 2 Diabetes: A Systematic Review and Meta-Analysis. Journal of the American Medical Association, 298, 2654-2664.

https://doi.org/10.1001/jama.298.22.2654

[25] Eliasson, B (2003) Cigarette Smoking and Diabetes. Progress in Cardiovascular Diseases, 45, 405-413. https://doi.org/10.1053/pcad.2003.00103

[26] Steinberg, A.G. (2010) Heredity and Diabetes. Eugenics Quarterly, 2, 26-30. https://doi.org/10.1080/19485565.1955.9987216

[27] Rigalleau, V., Lang, J. and Gin, H. (2007) Étiologie et physiopathologie du diabète de type 2. EMC-Endocrinologie-Nutrition, 18, 1-12. 


\section{Appendices}

\section{Appendix 1: Survey Questionnaires for Type 2 Diabetics (Cases)}

1. ID:

2. Gender:

3. Place of investigation: $\square$ Campus University hospital $\square$ Sylvanus Olympio University hospital

4. Ethnicity:

5. Age: ..years

6. Weight: ... Kg

7. Height: meter

8. Profession:.

9. Area of residence: $\square$ Urban environment $\square$ Rural environment $\square$ Alternation

10. Before being diagnosed with diabetes, how long was your weekly physical activity?

$\square \quad$ Less than $75 \mathrm{~min} /$ week for endurance activities

$\square \quad$ More than $75 \mathrm{~min} /$ week for endurance activities

$\square \quad$ Less than $150 \mathrm{~min} /$ week for moderate intensity activities such as walking

$\square$ Greater than $150 \mathrm{~min} /$ week for moderate intensity activities such as walking

11. Did you smoke before you were diagnosed with diabetes?

$\square$ YES $\square$ NO

12. Before being diagnosed with type 2 diabetes, did you consume alcoholic products? $\square$ YES $\square$ NO

13. If yes, what was your average daily consumption of these alcoholic products?

$\square<2$ glasses of alcohol per day

$\square>2$ glasses of alcohol per day

$\square<3$ glasses of alcohol per day

$\square>3$ glasses of alcohol per day

14. Did you eat sugar before you were diagnosed with diabetes? $\square$ YES $\square$ NO

15. If yes, what was the average number of pieces consumed per day? ...... pieces/day

16. At what age were you diagnosed with diabetes? Years

17. Your parents (direct ascendants) are/were they diabetic?

$\square$ YES $\square$ NO

18. Did you have diabetic siblings?

$\square$ YES $\square$ NO

\section{Appendix 2: Survey Questionnaires for Non-Diabetics (Controls)}

1. ID:

2. Gender:

3. Place of investigation: $\square$ Campus University hospital $\square$ Sylvanus Olympio University hospital

4. Ethnicity:

5. Age: ...........years

6. Weight: ...........Kg

7. Height: ..........meter

8. Profession:. 
9. Area of residence: $\square$ Urban environment $\square$ Rural environment $\square$ Alternation

10. How long was your weekly physical activity?

$\square \quad$ Less than $75 \mathrm{~min} /$ week for endurance activities

$\square \quad$ More than $75 \mathrm{~min} /$ week for endurance activities

$\square \quad$ Less than $150 \mathrm{~min} /$ week for moderate intensity activities such as walking

$\square$ Greater than $150 \mathrm{~min} /$ week for moderate intensity activities such as walking

11. Did you smoke?

$\square$ YES $\square$ NO

12. Did you consume alcoholic products?

$\square$ YES $\square$ NO

13. If yes, what was your average daily consumption of these alcoholic products?

$\square<2$ glasses of alcohol per day

$\square \quad>2$ glasses of alcohol per day

$\square<3$ glasses of alcohol per day

$\square>3$ glasses of alcohol per day

14. Did you eat sugar?

$\square$ YES $\square$ NO

15. If yes, what was the average number of pieces consumed per day? .pieces/day

16. Your parents (direct ascendants) are/were they diabetic?

$\square$ YES $\square$ NO

17. Did you have diabetic siblings?

$\square$ YES $\square \mathrm{NO}$ 